\title{
A NOVA LEI NACIONAL DE ADOÇÃO - DESAFIOS PARA A REINSERÇÃO FAMILIAR
}

\author{
Milena Leite Silva* \\ Dorian Mônica Arpini"
}

\begin{abstract}
RESUMO. Este estudo teve como objetivo compreender o processo de reinserção familiar a partir da vigência da nova Lei Nacional de Adoção. Foram realizadas entrevistas com psicólogos e assistentes sociais trabalhadores de instituições de acolhimento, em uma cidade do Interior do Rio Grande do Sul. Utilizou-se a análise de conteúdo como método de análise. Os resultados evidenciaram que os profissionais buscam esgotar as possibilidades de reintegração na família de origem para, posteriormente buscar a família extensa, compreendendo esta busca como essencial no trabalho desenvolvido enquanto a criança está em acolhimento. Os profissionais indicam dificuldades na reinserção, devido aos muitos problemas que assolam as famílias, como doenças, dependências e fragilidades econômicas, os quais se encontram presentes também nas famílias extensas. As considerações finais revelam a reinserção como um desafio presente na prática dos profissionais dessas instituições, destacando-se forte vínculo entre eles e as famílias, o que indica uma mudança significativa no cenário da institucionalização de crianças.
\end{abstract}

Palavras-chave: Família; institucionalização; adoção.

\section{NEW NATIONAL ADOPTION LAW - CHALLENGES REGARDING FAMILY REINSERTION}

\begin{abstract}
This study aimed to understand the process of family reinsertion, considering the new National Adoption Law. Interviews with psychologists and social workers, who worked in youth shelters in a city of the interior of RS, were carried out. Data was analyzed through content analysis. Results evidenced that professionals try to exhaust the possibilities of reintegration in the family of origin. Only afterwards, they search for the extended family, understanding such search as central in the work developed when the child is in the shelter. The professionals highlight difficulties regarding reinsertion, due to problems that desolate families, such as illness, addictions and economic fragilities, problems that are present in the extended families as well. Final considerations reveal reinsertion as a challenge concerning the professional practices of people who work in such institutions, emphasizing the strong bonds between them and the families, indicating a scenery of change as regards children's institutionalization.
\end{abstract}

Key words: Family; institutionalization; adoption.

\section{NUEVA LEY NACIONAL DE ADOPCIÓN - DESAFÍOS PARA LA REINSERCIÓN FAMILIAR}

RESUMEN. Este estudio tuvo como objetivo comprender el proceso de reinserción familiar a partir de la vigencia de la Nueva Ley Nacional de Adopción. Fueron realizadas entrevistas con psicólogos y asistentes sociales, trabajadores de instituciones de acogimiento, en una ciudad del interior del RS. Se utilizó el análisis de contenido como método de análisis. Los resultados evidenciaron que los profesionales buscan agotar las posibilidades de reintegración en la familia de origen para, posteriormente, buscar la familia extensa, comprendiendo esta búsqueda como central en el trabajo desarrollado mientras el niño está en acogimiento. Los profesionales indican dificultades en la reinserción debido a problemáticas que molestan las familias como: enfermedades, dependencias y fragilidades económica, Problemáticas que se encuentran presentes también en las familias extensas. Las consideraciones finales revelan la reinserción como un desafío presente en la práctica de los profesionales de esas instituciones, destacándose el fuerte vínculo entre ellos y las familias, indicando un cambio significativo en la escena de la institucionalización de niños.

Palabras-clave: Familia; institucionalización; adopción.

Mestre em Psicologia pela Universidade Federal de Santa Maria.

\# Doutora em Psicologia Social pela Pontifícia Universidade Católica de São Paulo (2001). Atualmente é professora associada da Universidade Federal de Santa Maria. 
A importância da família para 0 desenvolvimento de seus membros e os investimentos que se fazem necessários para que ela possa desempenhar satisfatoriamente suas funções são questões já enfocadas pelas normas legais no Brasil (Brasil, 1988, 1990, 2006, 2009). Por outro lado, estudos apontaram um enfraquecimento das relações familiares e, simultaneamente, um esforço para a manutenção da família em meio a situações adversas, o que the permite reorganizar-se, reconstituir-se e dar conta de condicionantes externos que a afetam diretamente e, assim, permanecer definitivamente como uma estrutura importante para os relacionamentos humanos e sociais (Carvalho \& Almeida, 2003; Roudinesco, 2003; Sarti, 2005; Wagner, Pedrebon, Mossman \& Verza, 2005; Perucchi \& Beirão 2007; Roudinesco, 2003).

O direito à convivência familiar e comunitária está presente na Constituição de 1988 e no Estatuto da Criança e do Adolescente (Brasil, 1990), constituindo-se como mais uma estratégia para superar a cultura da institucionalização e valorizar a família. No ano de 2006, com o Plano Nacional de Promoção, Proteção e Defesa do Direito de Crianças e Adolescentes à Convivência Familiar e Comunitária, há um reforço na busca da proteção de crianças e adolescentes quando se centraliza a atenção na família. Este Plano busca fortalecer a família para que esta seja auxiliada e assim possa manter um cuidado continuado em relação aos seus filhos.

O Plano Nacional (Brasil, 2006) tem como proposta formular políticas de fortalecimento das famílias que possibilitem a crianças e adolescentes ter assegurados, no interior da família, os elementos necessários para seu desenvolvimento integral. A confluência de estudos, leis e diretrizes políticas que se referem às atribuições e responsabilidades da família e do Estado apontam para uma mudança de paradigmas ocorrida nas duas últimas décadas (Rizzini \& Rizzini, 2004). Tais mudanças resgatam a centralidade da família e do Estado nas questões relativas ao desenvolvimento de crianças e adolescentes e à convivência familiar e comunitária.

$\mathrm{Na}$ esteira dessas mudanças insere-se a nova Lei Nacional da Adoção (Brasil, 2009), a qual trouxe uma modificação na legislação antes existente no tocante ao retorno de crianças e adolescentes que se encontram em instituições às suas famílias, pois, de acordo com esta lei, o retorno à convivência familiar deve acontecer em um período máximo de dois anos, o que faz o tema da reinserção familiar ganhar destaque.

Tal medida imposta pela nova lei é importante, já que dados apontados por Silva (2004), em pesquisa realizada nas entidades de acolhimento brasileiras, revelam que mais da metade das crianças permanece nas instituições por mais de dois anos, muitas delas saindo desses locais quando completam 18 anos. Tal estudo evidenciou ainda a dificuldade encontrada, mesmo após a implementação do Estatuto da Criança e do Adolescente (Brasil,1990), em fazer do afastamento de crianças e adolescentes de suas famílias algo breve e excepcional.

A nova lei define que a entidade de acolhimento deve se responsabilizar por este resgate dos vínculos (Brasil, 2009, art. 19, I) e pelo limite de tempo para sua concretização, o que parece se constituir como uma das ações importantes para alcançar os princípios da brevidade e da excepcionalidade ainda não alcançados. Os psicólogos e os assistentes sociais que trabalham nas instituições de acolhimento passam a assumir a responsabilidade pela reintegração familiar das crianças e adolescentes acolhidos. Na nova lei de adoção ficou estabelecido que as entidades devem desenvolver programas de acolhimento institucional nos quais se adote o princípio da preservação dos vínculos familiares e da promoção da reintegração familiar (Art. 92, §l). A convivência familiar e comunitária (Art. 19) foi reforçada através de três incisos, os quais estabelecem que a situação jurídica da criança acolhida em uma instituição deve ser reavaliada a cada seis meses (\$10), o tempo máximo de permanência em acolhimento institucional será de dois anos, salvo comprovada necessidade que atenda ao interesse da criança (\$20), e a manutenção ou reintegração de criança ou adolescente à sua família terá preferência em relação a qualquer outra ação (§3o).

Vê-se, assim, que com a nova lei, quando uma criança for acolhida, sua família deverá ser auxiliada em suas necessidades para que a convivência familiar seja restabelecida com a maior brevidade possível, garantindo-se a preservação dos laços. Não obstante, pode-se perceber que há dificuldades no trabalho com famílias, pois quase dez anos depois da Declaração do Ano Internacional da Família 
(1994), uma pesquisa revelou dados preocupantes: apenas $14,1 \%$ das instituições de acolhimento no país desenvolviam trabalhos voltados à família (Silva, 2004). Em concordância com essa realidade, Bernardi (2010), através de um trabalho de oficinas realizadas com profissionais ligados ao acolhimento institucional de crianças e adolescentes em São Paulo, menciona que o trabalho com as famílias foi sinalizado como uma das maiores dificuldades do dia a dia dessas instituições, o que é corroborado pelos estudos de Arpini e Quintana(2009), Silva (2004) e Silveira (2002).

No que tange à reintegração familiar, esta é entendida aqui como o retorno de crianças e adolescentes às suas famílias após um período de separação. Esse retorno é baseado no artigo 227 da Constituição Federal (1988), o qual estabelece que "toda criança tem direito à convivência familiar e comunitária." Pensar em reintegração familiar pode ser uma tentativa acertada de romper o equívoco histórico do incentivo à institucionalização e à concepção da incapacidade da família de cuidar de seus filhos (Rizzini \& Rizzini, 2004). Sabe-se que a relação entre institucionalização e família foi carregada de desencontros, marcados pelo afastamento da família em relação à realidade institucional, aspecto que pode ser explicado pela visão estigmatizada que se construiu da família, em especial das famílias pobres. A família era entendida como fonte do problema e seu afastamento como parte da perspectiva de solução, o que conduziu a práticas que levaram a um discurso desqualificado da família para a criança e também ao rompimento das relações familiares, de forma que, a partir da institucionalização, a família já não teria mais lugar na trajetória de vida da criança (Arpini \& Quintana, 2009).

Em concordância, Bernardi (2007) menciona que a institucionalização foi uma prática usual no Brasil para controlar a pobreza, porém muitas vezes se revestia de proteção social diante da suposição de que as famílias não estavam aptas a proteger e cuidar de seus filhos. $O$ rompimento dessa cicatriz presente na história das instituições de acolhimento traz em seu bojo a necessidade de construir uma nova relação entre as famílias e as instituições, já que o passado desses locais mostrou a segregação que a família sofreu ao longo dos anos (Arpini \& Quintana, 2009). Dessa forma, as ações calcadas na reconstrução das relações familiares podem trazer uma verdadeira transformação social das instituições de acolhimento (Associação Brasileira Terra dos Homens, 2002).

Se as famílias conseguem receber incentivos suficientes para retomarem as relações com seus filhos durante a medida de acolhimento institucional, passa-se às ações de retomada das relações de convivência de crianças e adolescentes com suas famílias, sejam estas as de origem, famílias extensas ou adotivas, processo chamado reintegração familiar, desligamento institucional, desabrigamento, desinstitucionalização, retorno à família/convivência familiar, reunificação familiar e reinserção familiar (Siqueira \& Dell'Aglio, 2007, Azor \& Vectore, 2008, Siqueira, Zoltowski, Giordani, Otero \& Dell'Aglio, 2010). A reintegração familiar é uma possibilidade de reconstruir a convivência familiar e comunitária de crianças e adolescentes, permitindo que estes voltem a conviver com suas famílias ou, em última análise, que possam ser inseridos em família substituta. Oliveira (2007, p. 107) reflete que "reintegrar sugere um trabalho de integrar de novo, isto é, juntar o que foi separado." Anteriormente à nova Lei Nacional de Adoção, nenhum agente dessas instituições foi responsabilizado diretamente por essa prática, através de uma legislação.

Embora o ECA (BRASIL, 1990) já aponte os princípios que devem ser adotados pelas entidades de atendimento (art. 92), entre eles a preservação dos vínculos familiares, integração em família substituta e a preparação gradativa para o desligamento, pode-se pensar que algumas dificuldades podem ter surgido nessas intervenções, já que foi preciso sistematizar a prática da reintegração familiar através da nova lei. Assim, as ações anteriormente existentes poderiam calcar-se na compreensão dada pela instituição, pela equipe técnica ou mesmo pelo profissional, acerca da importância dessa prática, a qual pareceu se constituir mais enquanto ação isolada do que como prática rotineira no interior das instituições.

Dessa forma, parece ter sido necessário acrescentar mais um princípio a ser adotado pelas entidades de atendimento: o princípio da promoção da reintegração familiar (art. 92, I) como norma a ser seguida em todas as instituições que acolhem crianças e adolescentes. Tal princípio institui algo que 
anteriormente poderia se restringir, arbitrariamente, a ações determinadas para esta ou aquela família, esta ou aquela criança e adolescente em condições de ser reintegrado. De agora em diante, tem-se que a reintegração deve ser promovida para todos e que as exceções dessa prática serão construídas no próprio esgotamento das ações direcionadas às famílias, às crianças e aos adolescentes. Assim, a colocação de uma criança em família substituta não pode ser pensada sem que antes se realizem todas as tentativas de reinserção na família natural. Esgotar todas as tentativas significa, neste momento da nova lei, traçar um plano de ação e investimentos nessa família no decorrer dos dois anos de acolhimento dos filhos, conciliando agilidade e competência. Isso certamente é um desafio diante de situações tão complexas.

\section{MÉTODO}

Para a realização do estudo, primeiramente foi feito um contato prévio com os psicólogos e os assistentes sociais das instituições de acolhimento de uma cidade do Interior do Rio Grande do Sul, momento no qual a proposta do estudo foi apresentada. As instituições acolhem crianças e adolescentes e, juntas, totalizavam 93 acolhidos no momento da realização da pesquisa. Os profissionais são oito, dos quais quatro são assistentes sociais e quatro são psicólogos, e representam a totalidade dos profissionais atuantes nestas áreas na cidade.

Nessa entrevista semidirigida de questões abertas (Turato, 2003), buscou-se compreender em profundidade as experiências dos psicólogos e assistentes sociais com a reintegração familiar das crianças e dos adolescentes. Houve uma troca dinâmica na condução da entrevista, isto é, as questões iam sendo colocadas ora pelo entrevistador ora pelo entrevistado, o que facilitou a coleta de informações baseada no discurso livre do entrevistado através da introdução de tópicos pelo entrevistador (Bleger, 1993).

Para conhecer em profundidade as reflexões dos psicólogos e assistentes sociais acerca da reintegração familiar foram utilizados os seguintes eixos norteadores: "Como é a relação da instituição com a família?"; "Como você vê a reintegração familiar das crianças e dos adolescentes?". As entrevistas foram gravadas e, posteriormente, transcritas na íntegra. A análise dos dados foi realizada através de análise de conteúdo (Bardin, 2004), a qual se caracteriza por um conjunto de instrumentos metodológicos que se aplicam aos discursos, analisando as comunicações, decompondo-as e elencando categorias.

Esta pesquisa está respaldada nas Diretrizes e Normas Regulamentadoras de Pesquisa Envolvendo Seres Humanos (Resolução 196/96 do Conselho Nacional de Saúde, Brasil,1996 ) e na Resolução n. ${ }^{\circ}$ 016/2000 do Conselho Federal de Psicologia (CFP, 2000), tendo parecer favorável do Comitê de Ética e Pesquisa da Instituição à qual as pesquisadoras estão vinculadas. Em função da preocupação ética e da garantia do anonimato dos participantes, não serão identificados o núcleo profissional e a instituição em que trabalham.

Os profissionais entrevistados são indicados pela letra $P$ e seus dados sociodemográficos demonstram que sua idade média é 31 anos e que possuem no mínimo dois anos e no máximo seis anos de atuação profissional, e, ainda, que - período mínimo de trabalho desses profissionais na instituição de acolhimento é de sete meses, e o máximo, de três anos.

\section{RESULTADOS E DISCUSSÃO}

\section{A busca pela família}

A reintegração familiar, como apontaram os psicólogos e assistentes sociais entrevistados, começa pelo trabalho incansável na procura de familiares dispostos a assumir os cuidados das crianças e dos adolescentes. Essa foi uma característica marcante na fala dos entrevistados, os quais parecem adotar uma postura firme e respaldada no asseguramento desse direito quando o tema remete à busca de familiares para o retorno e o direito à convivência familiar.

É o meu papel, é a minha obrigação, entendeu? Eu acho que isso traz muito essa busca da história da criança. Às vezes a juíza nos questiona, quando a gente fica demorando nessa busca, né? "Ah, mas vocês ainda estão buscando?"; daí eu sempre falo "Enquanto não forem esgotadas todas as formas de busca, doutora, eu vou buscar". Ela falou que eu sou... "ah, tu é... tu gosta de buscar", eu 
falei "não, eu gosto de ter uma história fidedigna. (P1)

Então é complicado, né, então a gente tem que correr atrás, sabe. Às vezes a gente revira o mundo, vamos até para outro Estado se for o caso. (P7)

Conforme se pode observar, os profissionais, em suas falas, demonstram valorizar a busca pela família. Eles "reviram o mundo atrás dela" e argumentam essa conduta perante o Juizado, por perceberem a importância de procurar todas as possibilidades desse resgate, reconhecendo a importância da família.

(...) eu acho que é uma coisa que é, né, a tendência assim, porque antes de colocar uma criança para adoção tem que ver, né, acabar com as chances. Todos os familiares que se têm ao redor tu tens que fazer tentativa antes de colocar para uma adoção. (P5)

Na verdade a gente faz toda uma busca. Quando o adolescente chega na Instituição, a gente faz um mapeamento da rede familiar - desde pai, mãe, irmão, irmã, tio, avô, avó, madrinha, padrinho, vizinhos que a pessoa se dê, pessoas conhecidas (...) A gente começa pela família biológica, depois vai pra família extensa, e em alguns casos acaba indo até para as relações da comunidade (...). (P3)

Nas falas acima percebe-se que os profissionais buscam assegurar 0 direito fundamental de crianças e adolescentes à convivência familiar e comunitária. Eles fazem referência ao esforço para conseguir estabelecer relações próximas com as famílias, pois entendem que cada dia longe de casa pode ser longo e sofrido para quem está acolhido. Esse esforço em buscar a família no decorrer da medida significa o investimento da equipe no desenvolvimento de ações necessárias para que a criança volte o mais breve possível e, principalmente, com melhores possibilidades de ser acolhida em casa. Se cada momento sofrido por estar longe de casa for utilizado pela equipe técnica como um tempo investido na reinserção, um tempo para se pensar em como ajudar a criança e a família a se reencontrarem, uma conexão se estabelecerá entre as crianças ou adolescentes, a família e a instituição.
O processo de reintegração familiar pode ser facilitado quando o laço existente entre a instituição e a família é forte e, principalmente, quando a instituição consegue trabalhar com a história da criança e de sua família, integrandoas, fazendo da instituição um verdadeiro caminho de volta ao lar. A busca da história "fidedigna" demonstra que há um grande envolvimento desses profissionais na busca da realidade vivencial dos acolhidos, superando-se uma concepção que foi marca das instituições do passado de que o melhor para a criança era deixar sua história para trás. Não obstante, nem todos os laços entre família e instituição tendem a se caracterizar pela força observada nas entrevistas assinaladas. Em muitos momentos os mesmos laços ainda podem se constituir como um desafio a ser superado nessa importante relação, tal como demonstra a fala a seguir, na qual se pode compreender que a cultura da família é vista como um fator limitador à ajuda profissional ofertada: " $E$ agora tem famílias também às vezes não adianta né, é a cultura daquela família." (P2).

Para além desse vínculo, entende-se que a avaliação das condições da família para receber o filho de volta é uma das premissas obrigatórias quando se pensa em reintegração. Nesse momento podem entrar em cena questões bastante complexas, como o que é uma família e como proceder para "avaliá-la" (Oliveira, 2007). Mesmo sabendo-se que família é um conceito plural, ainda persiste no Brasil uma dificuldade em "aceitar" as diferenças presentes nas novas configurações familiares e uma "insistência" na imposição do modelo patriarcal, pois, na dissolução da conjugalidade, a família extensa pode ser utilizada para preencher as lacunas deixadas pelo membro ausente (Amazonas, Damesceno, Terto \& Silva, 2003).

Aqui a gente tenta trabalhar ela num conjunto assim, mas às vezes vem a mãe, aí não vem o pai... né? Às vezes o pai não está ali e a mãe fica batalhando, não se entendem como uma unidade. (P1)

Para as famílias que estão inseridas na medida de acolhimento, essa concepção de família tradicional pode ser inatingível, uma vez que estas já vivenciam situações de desamparo e adversidades e encontram-se inseridas em um contexto social que por si só as distancia das concepções já cristalizadas. O estudo de Júnior 
e Andrade (2007) mostra a preocupação com a produção do discurso e das práticas profissionais, caracterizadas muitas vezes pela normatização e pela regulação, podendo-se inferir nesta fala a procura por um modelo de família tradicional, com "pai e mãe formando uma unidade". É importante ressaltar que, nas situações de vulnerabilidade familiar, a família fica desamparada pelas políticas sociais e ainda é responsabilizada por sua condição e pelo destino social de seus membros (Fante \& Cassab, 2007). A fala de um dos participantes da pesquisa aponta essa questão:

(...) Mas o trabalho que é feito aqui, lá fora tem a tendência a se perder; porque aqui na minha frente está tudo certo, a gente acompanha (...) Mas ela tem que sair daqui, depois do desacolhimento, e lá fora se confrontar com a pobreza, quase situação de miséria. (P6)

Essas famílias precisam manejar crises relativas à privação e à instabilidade, na maioria das vezes sem o conhecimento dos recursos parcamente existentes em suas comunidades (ABTH, 2002). Diante desse cenário, o Plano Nacional de Promoção, Proteção e Defesa do Direito de Crianças e Adolescentes à Convivência Familiar e Comunitária (2006) aponta que, para se operar com famílias, se faz necessário considerar e respeitar seus diferentes arranjos e composições.

Por outro lado, é importante considerar que cada profissional pode ter introjetado um modelo de família e esta "idealização" pode trazer dificuldade, à medida que o profissional se depara com modelos que podem afastar-se desse ideal. Neste sentido, Oliveira lembra que "quando vamos avaliar uma família, sabemos o quanto é difícil não nos deixar influenciar por valores e padrões sociais vigentes em nosso mundo sobre as formas de cuidado, atenção e educação no trato dos filhos pelas famílias" (2007, p. 107).

Tu fazes um trabalho com os pais, geralmente é só a mãe também, porque o pai nunca está presente, ou o pai já morreu, ou na grande maioria o pai já não faz parte da família - ou por estar preso, ou por já ter falecido, ou por essa mãe... enfim, ser solteira, e engravidou e não conhece nem o pai - isso representa grande parte do nosso público. (P6)
Neste contexto vale ressaltar que a família, independentemente do seu arranjo, é o espaço privilegiado para a sobrevivência, o desenvolvimento e a proteção integral de crianças e adolescentes (UNICEF, 2007).

Nesse sentido, quando a busca e o trabalho realizado apontarem a possibilidade de retorno, entende-se que também será necessário trabalhar as angústias em relação à criança ou adolescente que chegam após um período de institucionalização (Arpini \& Quintana, 2009), acionando os recursos familiares para compreender quais são os possíveis obstáculos relacionados à integração deste membro e às capacidades da família para oferecer esta acolhida.

\section{A família extensa}

Além da busca pela família de origem, a decisão judicial relativa à reinserção familiar de crianças e adolescentes atravessa diversas etapas de trabalho, incluindo a avaliação dos benefícios da saída da instituição para as crianças e os adolescentes (Oliveira, 2007), bem como as possibilidades e limitações encontradas nas famílias de origem para recebê-los. Se se identificam os limites para a reinserção, os quais serão apontados posteriormente neste trabalho, em função do olhar das equipes técnicas, os profissionais responsáveis lançam mão de uma alternativa proposta pela nova lei, a qual também valida a possibilidade de convivência familiar por meio da família extensa ou ampliada:

A gente tenta... porque às vezes volta; reintegrar para família de origem é bem difícil, dependendo do problema, mas a gente procura a família extensa, né, a ampliada que a gente diz. (P2)

A gente faz o trabalho com os pais, mas sempre com a possibilidade de colocar essa criança com os avós, com os irmãos, com a família ampliada. (...) Então geralmente tu marcas os dois, porque trabalha com as duas hipóteses já de largada. (P6)

Como se pode perceber, apesar dos esforços empreendidos para reintegrar a criança na família, existem situações em que a família não se encontra apta para receber a criança de volta. Entre as dificuldades estão presentes doenças, dependências (drogas, álcool) e a violência. Essas situações levam à necessidade 
de buscar a família extensa: "As questões de abuso normalmente se resolvem porque 0 adolescente é retirado daquela casa, ou a pessoa acaba se afastando; então tem a família extensa que a gente consegue inserir (...)." (P3)

Algumas equipes técnicas já trabalham com as duas hipóteses, de reinserção na família de origem ou na ampliada, como referido por P6, enquanto outras se detêm primeiro na família de origem. Caso esta reinserção não seja possível, busca-se trabalhar com a família ampliada, busca que se dá mediante diferentes intervenções, as quais demonstram que os profissionais se mobilizam pela garantia do direito à convivência familiar:

A gente está sempre atrás da família extensa, sabe, a gente está sempre procurando explicar. (...) Até em outras cidades! A gente estava fazendo contato por telefone, porque a gente não tinha como ir lá, e a gente ligava de duas a três vezes por semana, para lá! (...) A gente viu que tinham muito familiares em outras cidades, e era por telefone. (...) então a gente está sempre atrás deles, sabe. (...) Que antigamente, pelo que eu sei assim também, era só aquela questão de pai e mãe, né; mas hoje em dia, irmãos que já são casados se não tem também interesse, tios, até madrinha, tudo isso a gente faz contato e busca estar sempre passando para eles também (...) (P5)

A gente nunca teve problema com a família extensa; eles são nossos apoiadores e nossos parceiros; porque sempre a gente consegue uma alternativa, uma colocação em família ampliada. É a família que nos procurou, ou que a gente foi até a família e eles passaram as possibilidades. (...) $A$ família ampliada para nós é um sucesso, né. (P7)

Os profissionais das instituições pesquisadas indicam estar incluindo a família extensa ou ampliada, aquela composta por "parentes próximos com os quais a criança ou adolescente convive e mantém vínculos de afinidade e afetividade (Brasil, 2009, Art 25)." Nesse contexto, a nova lei e as práticas dos profissionais apontam para o reconhecimento deste lugar especial destinado à família, tanto a natural como a extensa. A família extensa é vista como fonte de apoio a crianças e adolescentes institucionalizados tanto quanto a família nuclear (Siqueira, Tubino, Schwarz \& Dell'Aglio, 2009).

Valorizar a família extensa através de lei (Lei 12.010/09) é legitimar uma prática já conhecida dos grupos populares para garantir o cuidado de seus filhos, segundo a qual a responsabilidade do grupo de parentesco pelas crianças e adolescentes fortifica os laços entre todos. Priorizar a família extensa é compreender que "as unidades econômica, emocional, residencial e outras podem não coincidir (Carvalho \& Almeida, 2003, p.110)." Nesse mesmo entendimento está o estudo de Silva, Mello e Aquino (2004), segundo o qual a singularidade de cada família precisa ser vista extrapolando-se os limites da coabitação; ou seja, para ajudar essas famílias é preciso reunir e explorar as ferramentas que elas mesmas já utilizam para dar conta de suas rotinas e, indo além das pessoas que moram na mesma casa, contar com o apoio de outros membros do grupo familiar. Levantar os recursos da rede familiar ampliada pode garantir a reintegração familiar, se a situação da família de origem trouxer obstáculos ao acolhimento:

(...) Até em questão do crack hoje, da
droga, me surpreendeu esse caso,
porque eram pessoas de mais de 40
anos que usavam. Essa avó já tinha
duas crianças dessa mãe, e não poderia
receber mais em virtude de não ter
condições também de saúde (...); mas
depois, conversando, né, com todo o
contexto ela aceitou receber, para os
irmãos ficarem com o outro. Então,
sempre que se é conversado com os
avós, se tem uma grande possibilidade
de logo ali já se solucionar a questão
(...). Então a gente busca muito isso, pra
não sair tanto de um contexto, de não
modificar tanto esse contexto (...) Mas
eu acho que são muito receptivos, mais
que os pais muitas vezes." (P6)

A família ampliada, por ser um prolongamento da rede existente na família de origem, pode, como revela a fala acima, auxiliar no sentido de garantir que a criança e o adolescente sintam-se ainda pertencentes e próximos aos seus núcleos familiares. Não obstante, cabe destacar que o recurso da família extensa também foi objeto de questionamento por parte de alguns profissionais, os quais percebem que a família ampliada pode apresentar tantas dificuldades econômicas 
quanto a família de origem, compreendendo que a miserabilidade das famílias se apresenta como um fator que dificulta a reinserção:

Ah, tu vai ter que botar lá, o erro da Lei de Adoção, que eu acho: é a questão de que adolescente tem que ir para família ampliada - eu discordo. (...) eu acho o seguinte: que a questão de ir para família ampliada é relativa. (...) Mas será que essa família ampliada tem as mínimas condições de ficar com essa criança? (...) Porque é uma bucha, a gente não pode dizer que não. É uma bucha sim! Aquele adolescente está desestabilizado quando vai para aquela família ampliada, e eles estão... são gente muito humilde, já têm que dividir a pouca comida com mais aquele outro que está ali, e daí aquela criatura está me incomodando, ele já cria um conflito, aquela penca de filho (...) (P4)

Problematizando a reinserção familiar na família extensa, um dos profissionais aponta para a vulnerabilidade desta, pois ela também se encontra diante de desafios cotidianos de sobrevivência capazes de desencadear situações de cobrança e violência, o que não ajuda a criança e o adolescente. Neste sentido, levar em conta a fragilidade da família extensa parece ser um aspecto central. Outro ponto é a questão do preparo para receber as crianças e os adolescentes de volta, pois uma pesquisa realizada por Siqueira et al. (2010) constatou, através da análise da reinserção familiar de três adolescentes, que não houve uma preparação prévia para o retorno nem dos adolescentes nem dos familiares. Somando-se a essa falta de preparo, as dificuldades sociais e econômicas persistentes podem dificultar ainda mais 0 convívio familiar.

A gente tenta... porque às vezes volta. Reintegrar para família de origem é bem difícil, dependendo do problema, mas a gente procura a família extensa, né, a ampliada que a gente diz (...). Mas o que que acontece: geralmente são famílias numerosas, são famílias carentes de... de condições financeiras, carentes de políticas públicas, ãh, não têm interesse por mais uma criança. Ou seja, essa criança vai viver só pra ser excluída da família. Depois "ah tua mãe era isso, tua mãe era aquilo"; ser violentada psicologicamente, ser tratada diferente das outras. (...) Eu já tive várias devoluções da família ampliada. (P2)

Talvez as evidências da devolução colocada pelo profissional estejam denunciando a complexidade do fenômeno da reintegração e os aspectos já apresentados anteriormente com relação às fragilidades dessas famílias. Isso indica que deve haver muito cuidado quando se pretende aplicar a reintegração familiar na família extensa/ampliada. Em outra entrevista, o profissional menciona que não é a questão social das famílias que pode prejudicar a reinserção, mas a chegada de novos membros em uma família que pode não estar preparada para recebê-los, remetendo assim para a importante questão da preparação das famílias ampliadas que receberão crianças ou adolescentes que estão se desligando do acolhimento:

Essa família aconteceu assim oh: eles tinham um patamar de vida, aconteceu alguma coisa - que não dá bem pra entender, mas nós acreditamos que seja o uso do pai de drogas (...) e aí os filhos se perderam. São dois. $E$ aí a gente começou colocando eles com os irmãos, num irmão, o único irmão que tentou ficar com eles. Mas a cunhada se desestabilizou. Por quê? Porque estava construindo uma vida, porque só tinha um filho único, e aí ganhou mais dois filhos, e a responsabilização, e aí a familia que acolheu eles se desestruturou. Então nós tivemos que retirar, e agora eles estão em acolhimento institucional novamente." (P1)

Em outras situações, além das dificuldades sociais e econômicas e da dinâmica familiar, 0 vínculo entre a família de origem e a ampliada também é fator que pode dificultar a reintegração familiar:

(...) às vezes tem vínculo com a criança, e muitas vezes a família extensa ela tem medo de represália dos pais - é tranquilo com as crianças, mas "bah, fulano quando sair da cadeia", no caso, se o pai estiver recluso. Muitas vezes isso é um impasse, dos pais usarem as crianças pra chantagear; então às vezes fica muito complicado, por mais que tu sensibilizes a família... "bah, mas eu não quero encrenca com o fulano"(...). 
Aparece muito claro, que por mais que goste não quer se incomodar. (P8)

Essas dificuldades, trazidas pelos novos referenciais legislativos referentes à responsabilidade da família e ao direito das crianças e adolescentes de permanecer em seu núcleo familiar e comunitário, evidenciam a permanência de um descompasso existente no Brasil acerca da importância da família e da existência de reais incentivos para que ela possa cumprir com sua parte nessa responsabilização (Rizzini, Rizzini, Naiff \& Baptista, 2006). A família ampliada, assim como a de origem, também pode se ver em apuros para sobreviver, e a chegada de mais um membro, além das responsabilidades que isto implica, também pode representar "encrenca", como referido no trecho anterior.

Essa premissa pode representar uma dificuldade ainda existente nas famílias: a de fazer valer o princípio do "melhor interesse da criança", um direito constitucional absolutamente fundamental. Por outro lado, como manter essa prioridade e assumir uma "encrenca", ou seja, um conflito com a família de origem e ainda não contar com o apoio do Estado para superar essas possíveis dificuldades? Nesse contexto, é importante considerar tanto a presença da vulnerabilidade ${ }^{1}$ nas famílias extensas quanto a importância do respaldo das políticas públicas de apoio a estas famílias quando acolhem as crianças e os adolescentes, compreendendo que se somam problemas e desafios que devem ser amplamente entendidos.

\section{CONSIDERAÇÕES FINAIS}

A reinserção familiar mostrou-se como uma prática que tem desafiado os psicólogos e assistentes sociais das instituições de acolhimento institucional pesquisadas. Como toda nova atividade profissional que começa a ser desempenhada, ela ainda está sendo construída por esses atores, que começam a delinear uma forma de reinserir crianças e adolescentes na vivência familiar. Nesse desenho da nova prática, a busca constante pelo esgotamento das possibilidades de convivência

\footnotetext{
1 "Grupos ou indivíduos que, por diversos motivos, são mais atingidos pelos efeitos das desigualdades socioeconômicas e à precariedade das políticas públicas” (Rizzini, Rizzini, Naiff, Baptista, 2007, p18)
}

familiar foi bastante destacada, acontecendo uma forte vinculação entre os psicólogos e assistentes sociais e a família, o que parece contribuir para que esta se sinta, pouco a pouco, mais à vontade para falar de suas dificuldades e, consequentemente, mais receptiva às orientações e encaminhamentos propostos pelos profissionais.

Não obstante, mesmo com a soma de esforços para reintegração familiar, foram apontadas pelos profissionais situações em que a família não se encontra apta para receber a criança de volta, principalmente devido a doenças, dependências (drogas, álcool) e violências. Essas situações levam à necessidade de buscar a família extensa, a qual muitas vezes é vista como semelhante à família de origem, ou seja, vulnerável, uma vez que as dificuldades econômicas e sociais também podem estar presentes na família extensa. De qualquer forma, é importante destacar o movimento dos profissionais com vistas a contemplar os aspectos presentes na nova lei, mas sem deixar de evidenciar as dificuldades que referem encontrar.

Além dos aspectos pontuados, os profissionais referem experiências bemsucedidas de reintegração familiar, as quais têm sido por eles acompanhadas, dentro da perspectiva da nova lei, a qual propõe a continuidade no acompanhamento dos casos após a saída da medida de acolhimento. Entende-se este aspecto como fundamental para assegurar o êxito da reintegração familiar, considerando-se a complexidade das situações familiares dos envolvidos.

Passados quatro anos da promulgação da nova Lei Nacional de Adoção, o que pode ser destacado aqui é que o tema da reintegração familiar é uma realidade presente no acolhimento institucional, e isso é, sem dúvida, resultado de novas práticas profissionais.

Destaca-se, não obstante, a importância de novos estudos relacionados ao tema, em face das muitas mudanças que se impõem a esse contexto, para levar à construção de novos saberes e novos fazeres, os quais devem ser alvo de constantes reflexões.

\section{REFERÊNCIAS}

Amazonas, M.C.L.A., Damasceno, P.R., Terto, L.M.S., \& Silva, R.R. (2003). Arranjos familiares de crianças das 
camadas populares. Psicologia em Estudo, 8 (num.esp), $11-20$.

Arpini, D.M., \& Quintana, A.M. (2009). Família e instituições de abrigo: reconstruindo relações. In: D.M. Arpini (Org.) Psicologia, família e instituição (pp. 9-28). Santa Maria: Editora UFSM.

Associação Brasileira Terra dos Homens (2002). Do abrigo à família. Serie Em defesa da convivência familiar e comunitária. 3a Ed, Rio de Janeiro: Booklink.

Azor, A.M.G.C.C.V. \& Vectore, C. (2008). Abrigar/desabrigar: conhecendo o papel das famílias nesse processo. Estudos de Psicologia, 25(1), 77-89.

Bardin, L. (2004). Análise de conteúdo. (L. A. Reto \& A. Pinheiro, Trad.). São Paulo: Edições 70, Livraria Martins Fontes (Obra original publicada em 1977).

Bernardi, D.C.F. (2007). Apresentação para a segunda edição. In: R.C.S.Oliveira, (Coord). Quero voltar para casa: o trabalho em rede e a garantia do direito à convivência familiar e comunitária para crianças $e$ adolescentes que vivem em abrigo.2 ${ }^{\mathrm{a}} \mathrm{Ed}$, São Paulo : AASPTJ - SP, s/p. Recuperado em 09 agosto, 2011, de http://www.neca.org.br/wp-content/uploads/Livro6.pdf.

Bernardi, D.C.F. (2010). Famílias em situação de vulnerabilidade. In: D.C.F. Bernardi, (Coord) Cada caso é um caso: estudos de caso, projetos de atendimento. 1. ed., São Paulo : Associação Fazendo História: NECA Associação dos Pesquisadores de Núcleos de Estudos e Pesquisas sobre a Criança e o Adolescente, Coleção Abrigos em Movimento. Recuperado em 11 outubro, 2011,

http://www.fazendohistoria.org.br/downloads/5 cada cas a_e_um_caso.pdf.

Bleger, J. (1993). Temas de psicologia: entrevista e grupos. São Paulo: Martins Fontes.

Brasil. Presidência da República. (2006). Plano Nacional de Promoção, Proteção e Defesa do Direito de Crianças e Adolescentes à Convivência Familiar e Comunitária. Secretaria Especial dos Direitos Humanos. Brasília-DF: Conanda.

Carvalho, I.M.M., \& Almeida, P.H. (2003). Família e Proteção Social. São Paulo em perspectiva, 17(2), 109-122.

Constituição da República Federativa do Brasil de 1988. (1988). Brasília, DF: Presidência da Republica. Recuperado em 20 abril, 2011, de http://www.planalto.gov.br/ccivil_03/constituicao/constitui $\%$ C3\%A7ao.htm.

Fante, A. P., \& Cassab, L. A. (2007). Convivência familiar: um direito à criança e ao adolescente institucionalizado. Revista Textos \& Contextos, 6 (1), 154-174.

Fundo das Nações Unidas para a Infância (2007). Situação da infância brasileira 2007. Índice de desenvolvimento infantil. Recuperado em 10 julho, 2010, de http://www.unicef.org.br/

Júnior, N.G.S.S., \& Andrade, A.N. (2007). É melhor para você! Normatização social da infância e da família no Brasil. Revista do Departamento de Psicologia da UFF, 19 (2), 423-438.

Lei $n^{\circ}$ 12.010, de 3 de agosto de 2009. (2009, 3 de agosto). Dispõe sobre adoção; altera as Leis nำ 8.069 , de 13 de julho de 1990 - Estatuto da Criança e do Adolescente,
8.560, de 29 de dezembro de 1992; revoga dispositivos da Lei $n^{\circ}$ 10.406, de 10 de janeiro de 2002 - Código Civil, e da Consolidação das Leis do Trabalho - CLT, aprovada pelo Decreto-Lei $n^{\circ} 5.452$, de $1^{\circ}$ de maio de 1943; e dá outras providências. Brasília, DF: Casa Civil, Subchefia para assuntos jurídicos. Recuperado em 23 setembro, 2009,

http://www.planalto.gov.br/ccivil 03/ Ato20072010/2009/Lei/L12010.htm

Lei $n^{\circ}$ 8.069, de 13 de julho de 1990. (1990, 13 de julho). Dispõe o Estatuto da Criança e do Adolescente e dá outras providências. Brasília, DF: Casa Civil, Subchefia para assuntos jurídicos. Recuperado em 19 setembro, 2000, http://www.planalto.gov.br/ccivil_03/leis/L8069.htm

Oliveira, R.S. (2007). Quero voltar para casa. São Paulo: AASPTJ/SP. Recuperado em 15 agosto, 2011 de http://www.neca.org.br/wp-content/uploads/Livro6.pdf.

Perucchi, J., \& Beirão, A. M. (2007). Novos arranjos familiares: paternidade, parentalidade e relações de gênero sob o olhar de mulheres chefes de família. Psicologia Clínica, 19(2), 57-69.

Rizzini, I. \& Rizzini, I. (2004). A institucionalização de crianças no Brasil: percurso histórico e desafios do presente. Rio de Janeiro: Ed PUC-Rio; São Paulo: Loyola.

Rizzini, I., Rizzini, I., Naiff, L., \& Baptista, R. (2006). Acolhendo crianças e adolescentes: experiências de promoção do direito à convivência familiar e comunitária no Brasil. São Paulo: Cortez; Brasília, DF: UNICEF; CIESPI; Rio de Janeiro, RJ: PUC-RIO Ed.

Roudinesco, E. (2003). A família em desordem. Rio de Janeiro: Zahar.

Sarti, C. A. (2005). A Família como espelho - um estudo sobre a moral dos pobres. São Paulo: Cortez.

Silva, E. R. A. (2004). A construção do direito à convivência familiar e comunitária no Brasil. In: E.R.A. Silva (Coord). $O$ direito à convivência familiar e comunitária: os abrigos para crianças e adolescentes no Brasil (pp. 287-302). Brasília: IPEA/CONANDA.

Silva, E.R.A., Mello, S.G., \& Aquino, L.M.C. (2004). Os abrigos para crianças e adolescentes e a promoção do direito à convivência familiar e comunitária. In: E.R.A. Silva (Coord). $O$ direito à convivência familiar e comunitária: os abrigos para crianças e adolescentes no Brasil (pp.209-242). Brasília: IPEA/CONANDA.

Silveira, S. C. (2002). Família é para todos - A perspectiva de meninos institucionalizados. In: Wagner, A. (Coord.) Família em Cena: tramas, dramas e transformações. (pp. 54-74). Petrópolis: Vozes.

Siqueira, A. C., \& Dell'Aglio, D. D. (2007). Retornando à família de origem: fatores de risco e proteção no processo de reinserção familiar de uma adolescente institucionalizada. Revista Brasileira de Crescimento e Desenvolvimento Humano, 17(3), 134-146.

Siqueira, A.C., Tubino, C.L., Schwarz, C. \& Dell'Aglio, D.D. (2009). Percepção das figuras parentais na rede de apoio de crianças e adolescentes institucionalizados. Arquivos Brasileiros de Psicologia, 61(1), 176-190.

Siqueira, A.C., Zoltowski, A.P., Giordani, J.P., Otero, T.M., \& Dell'Aglio, D.D.(2010). Processo de reinserção familiar: 
estudo de casos de adolescentes que viveram em instituição de abrigo. Estudos de Psicologia, 15(1), 0715.

Turato, E.R. (2003). Tratado da Metodologia da Pesquisa Clinico-Qualitativa. Petrópolis, Rio de Janeiro: Vozes.

Wagner, A., Predebon, J., Mosmann, C., \& Verza, F. (2005). Compartilhar tarefas? Papéis e funções de pai e mãe na família contemporânea. Psicologia: Teoria e Pesquisa 21(2), 181-186.

Endereço para correspondência: Milena Leite Silva. Rua Silva Jardim, 1269, ap. 01, Bairro Rosário, CEP 97010-492, Santa Maria-RS, Brasil. E-mail: milenaleitesilva@hotmail.com. 